\title{
Big Data-oriented Wheel Position and Geometry Calculation for Cutting Tool Groove Manufacturing based on Al Algorithms
}

\section{Li Guochao ( $\square$ liguochaolaile@126.com )}

Jiangsu University of Science and Technology https://orcid.org/0000-0001-6917-084X

\section{Zhigang Liu}

Jiangsu University of Science and Technology

Jie Lu

Jiangsu University of Science and Technology

Honggen Zhou

Jiangsu University of Science and Technology

Li Sun

Jiangsu University of Science and Technology

\section{Research Article}

Keywords: Groove manufacturing, Multiple output regression, Al, Big data

Posted Date: November 3rd, 2021

DOI: https://doi.org/10.21203/rs.3.rs-1029477/v1

License: (c) (1) This work is licensed under a Creative Commons Attribution 4.0 International License. Read Full License 


\title{
Big Data-oriented Wheel Position and Geometry Calculation for Cutting Tool Groove Manufacturing Based on AI
}

\author{
Algorithms \\ Guochao $\mathrm{Li}^{1,2^{*}}$, Zhigang Liu ${ }^{1,2}$, Jie Lu ${ }^{1,2}$, Honggen Zhou $^{1,2}$, Li Sun ${ }^{1,2}$ \\ 1 School of Mechanical Engineering, Jiangsu University of Science and Technology, Zhenjiang, 212003, PR China \\ 2 Jiangsu Provincial Key Laboratory of Advanced Manufacturing for Marine Mechanical Equipment, Jiangsu University of \\ Science and Technology, Zhenjiang, 212003, PR China \\ * Corresponding author: Guochao Li (E-mail address: liguochaolaile@126.com).
}

\section{Abstract}

Groove is a key structure of high-performance integral cutting tools. It has to be manufactured by 5 -axis grinding machine due to its complex spatial geometry and hard materials. The crucial manufacturing parameters (CMP) are grinding wheel positions and geometries. However, it is a challenging problem to solve the CMP for the designed groove. The traditional trial-and-error or analytical methods have defects such as time-consuming, limited-applying and low accuracy. In this study, the problem is translated into a multiple output regression model of groove manufacture (MORGM) based on the big data technology and AI algorithms. The input are 34 groove geometry features and the output are 5 CMP. Firstly, two groove machining big data sets with different range are established, each of which is includes 46656 records. They are used as data resource for MORGM. Secondly, 7 AI algorithms, including linear regression, $k$ nearest-neighbor regression, decision trees, random forest regression, support vector regression and ANN algorithms are discussed to build the model. Then, 28 experiments are carried out to test the big data set and algorithms. Finally, the best MORGM is built by ANN algorithm and the big data set with a larger range. The results show that CMP can be calculated accurately and conveniently by the built MORGM.

Keywords: Groove manufacturing; Multiple output regression; AI; Big data

\section{Declarations}


Funding This work was supported by the Natural Science Foundation of Jiangsu Province of China (No. BK20160563) and the National Natural Science Foundation of China (No. 51605207)

Competing interests The authors declare that they have no competing interests.

Data availability All data generated or analyzed during this study were available by emailing to author. (liguochaolaile@126.com).

Authors contributions Guochao Li proposed the main analysis ideas, established the multiple output regression model for groove manufacturing, and carried out the CMP can be calculated accurately and conveniently by the built MORGM, is the main contributor of the paper. Zhigang Liu and Jie Lu participated in data collation and analysis. Honggen Zhou and Li Sun helped to read and approve the final manuscript.

Ethical approval Not applicable.

Consent to participate Not applicable.

Consent to publish Not applicable. 


\section{Introduction}

Groove is one of the most important structure of integral cutting tools, such as end mill, drill and reamer. Because it determines the strength and sharpness of cutting edges, as well as the chip removal ability. Groove has to be machined by 5-axis grinding machine due to its complex spatial surface and tough blank material. With the emergence of diverse groove geometries, how to set the crucial manufacturing parameters (CMP), including grinding wheel positions and geometries, to get the desired groove geometry has been an urgent problem for groove machining and cutting tool manufacture.

During the groove grinding process, the wheel position, wheel geometry and groove geometry follow the enveloping theory, namely the common normal at the contact point between the wheel and the groove surface must intersect with the tool axis[1]. Accordingly, mathematical relationships (i.e., enveloping equation) between the wheel and groove could be deduced. However, the enveloping equation was a transcendental equation which was hard to be solved. To solve the problem, two methods were mainly used: divide-and-conquer method and objective function[2].

The divide-and-conquer method was an iterative approach. By finding the different influence rates of the wheel position on the machined groove parameters, the wheel position was searched step by step. Based on the directly proportional relationship between the wheel position and the two groove parameters rake angle and core radius, Kim et al. [3], Rababah et al.[4] and Ren et al. [5]roughly searched and slightly adjusted the wheel position by the rake angle and the core radius respectively and successively. Furthermore, the calculation precision was improved by Nguyen et al. [6] and Pham et al. [7]. Differently, Xiao et al.[8], Tang et al. [9] and Jia et al. [10] changed the calculation order: the core radius was considered first, followed by the rake angle. Chen et al. [11] take the calculation procedure: core radius, groove width and then rake angle.

The objective function method was an optimization approach to calculate the wheel position until the function was approximately solved. Wang et al. [12] built an 
objective function by the error of rake angle, core radius and groove width between the desired and the machined groove. Then, the 1A1-type wheel position was obtained by searching the minimum value of the function. Ren et al. [13] created a system of nonlinear equations to calculate the wheel position, and the wheel position can be calculated accurately to ensure the accuracy of the groove parameters: rake angle, core radius and flute width. Karpuschewski et al. [14] and Li et al. [15] built the objective function with machine errors and successfully searched the wheel position using intelligent algorithms, such as PSO and NPSO. Habibi et al. [16] calculated the established constraint equations by using Newton iteration algorithm to improve the speed and reliability of the calculation.

Besides, Fang [17]discussed an approach to calculating the wheel location and orientation for CNC Flute-Grinding by re-formulating the wheel's determination model and analyzing the geometrical constraints for interference, over-cut and undercut in a unified framework. The model was integrated with the evolution algorithm and local search operator to optimize the wheel's location and orientation. Li [2]built a general model is established to calculate the wheel path for complex groove machining based on a mathematical optimization model, which have three constraints and one objective. Considering that the worn wheel would result in groove grinding error without a proper compensation, Liu[18, 19] proposed a compensation algorithm of worn wheel by analyzing the boundary contact condition which is influenced by wheel wear. Uhlmann[20] presented a method for designing application-oriented grinding wheels to improve the productivity and the quality of grinding processes. So that, grinding wheels with different layers over its width were developed to compensate the varying and complex contact conditions. Wasif [21]proposed an approach to determine the non-standard grinding wheel that can be economically produced or dressed to accurately grind the end-mill cutters using the five-axis CNC grinding process.

In conclusion, the method discussed above focused on solving complex equation set, which was time-consuming and limited-applying. Essentially, the groove machining problem could be translated into a multiple output regression problem. The 
input parameters were groove geometry features and the output targets were wheel geometry and position. Considering that artificial intelligence (AI) algorithms was good at building regression models, the study aimed to build a multiple output regression model of groove manufacture (MORGM) based on AI algorithms and big data of groove machining processes.

\section{Big data generation and feature extraction}

\subsection{Modeling of groove machining process}

The cutting tool groove was generated by the principle of "envelope forming". Namely, the groove was machined by the profile of the grinding wheel, which moved helically around the tool axis. Thus, the groove was determined by the grinding wheel geometry, as well as its position that relative to the tool.

The grinding wheel process was modeled by space analytical geometric theory, as presented in Fig.1. Two cartesian coordinate systems were established. One was the

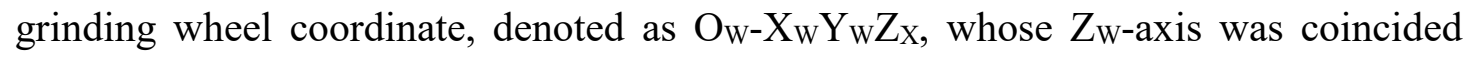
with the wheel axis, and $\mathrm{X}_{\mathrm{W}}-\mathrm{Y}_{\mathrm{W}}$ plane was coincided with the end face of the wheel. The other was the tool coordinate, denoted as $\mathrm{O}_{\mathrm{T}}-\mathrm{X}_{\mathrm{T}} \mathrm{Y}_{\mathrm{T}} \mathrm{Z}_{\mathrm{T}}$, whose $\mathrm{Z}_{\mathrm{T}}$-axis was coincided with the tool axis, and $\mathrm{X}_{\mathrm{W}}-\mathrm{Y}_{\mathrm{W}}$ plane was coincided with the end face of the tool. During the machining process, the $\mathrm{O}_{\mathrm{T}}-\mathrm{X}_{\mathrm{T}} \mathrm{Y}_{\mathrm{T}} \mathrm{Z}_{\mathrm{T}}$ was motionless, while the $\mathrm{O}_{\mathrm{W}}-\mathrm{X}_{\mathrm{W}} \mathrm{Y}_{\mathrm{W}} \mathrm{Z}_{\mathrm{W}}$ was moved helically around the tool axis together with the wheel.

The wheel position was defined by 3 parameters: the distance between $\mathrm{X}_{\mathrm{W}}$ and $\mathrm{X}_{\mathrm{T}}$ (i.e., $\Delta y$ ), the distance between $\mathrm{Z}_{\mathrm{W}}$ and $\mathrm{Z}_{\mathrm{T}}$ (i.e., $\Delta x$ ), and the angle that rotated from

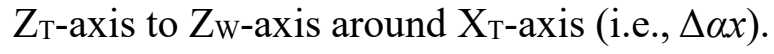

The 1A1 type grinding wheel geometry was expressed by 3 variable parameters: the thickness $B_{\mathrm{W}}$, the taper angle $\theta_{\mathrm{W}}$ and the fillet radius $g r$. 


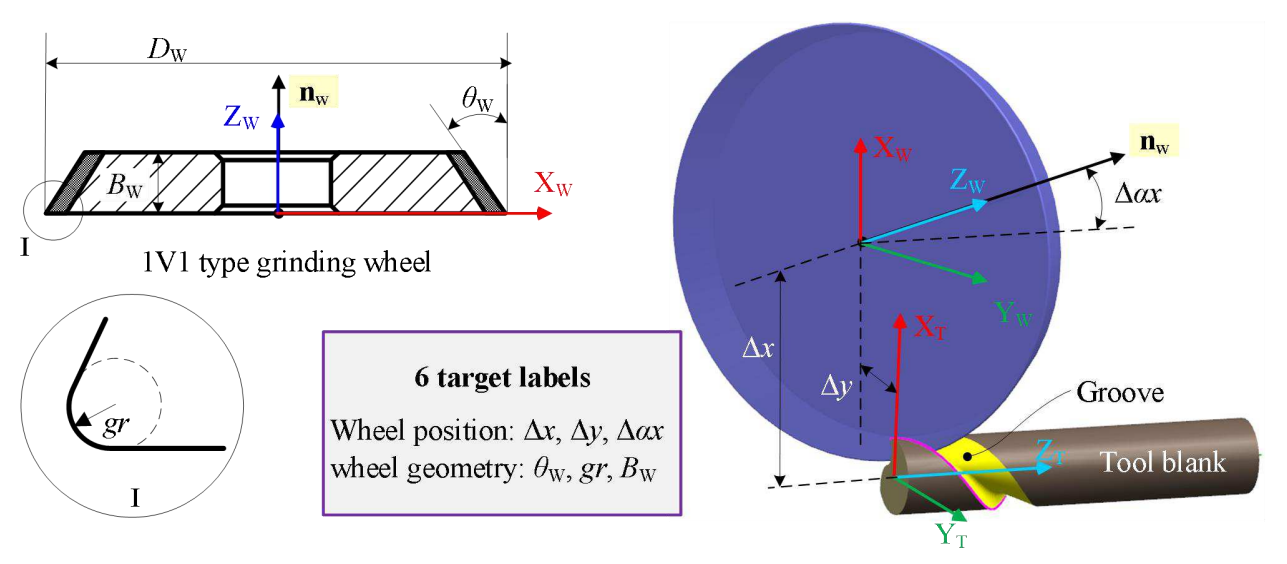

Fig.1 Groove machining process

According to the method introduced in reference [15], the groove geometry could be calculated with the known wheel geometry and its position. And the groove was predicted by discrete points that belong to a series of annuluses, which had the same width and different radius. Then, the groove profile as well as its features could be defined by these points.

The groove in the reference was defined by only 3 features, namely rake angle, core radius and groove width. Obviously, three features were too few for AI algorithms to establish the MORGM. Therefore, much more features should be defined. As presented in Fig.2, 34 features were used in the study, including the commonly used two features core radius $\left(r_{\mathrm{c}}\right)$ and groove width $(\Phi)$, and the Euclidean distance between points that located on the groove profile. In this study, 30 annuluses were used so that 61 points were deduced. The first Euclidean distance $d_{1}$ was the distance between $p_{1}$ and $p_{\mathrm{rc}}$, the second $d_{2}$ was the distance between $p_{61}$ and $p_{\mathrm{rc}}$. Then, other Euclidean distances were between the two points that located in the same annulus, which were denoted as $d_{3}, d_{4}, d_{5} \ldots d_{32}$. 


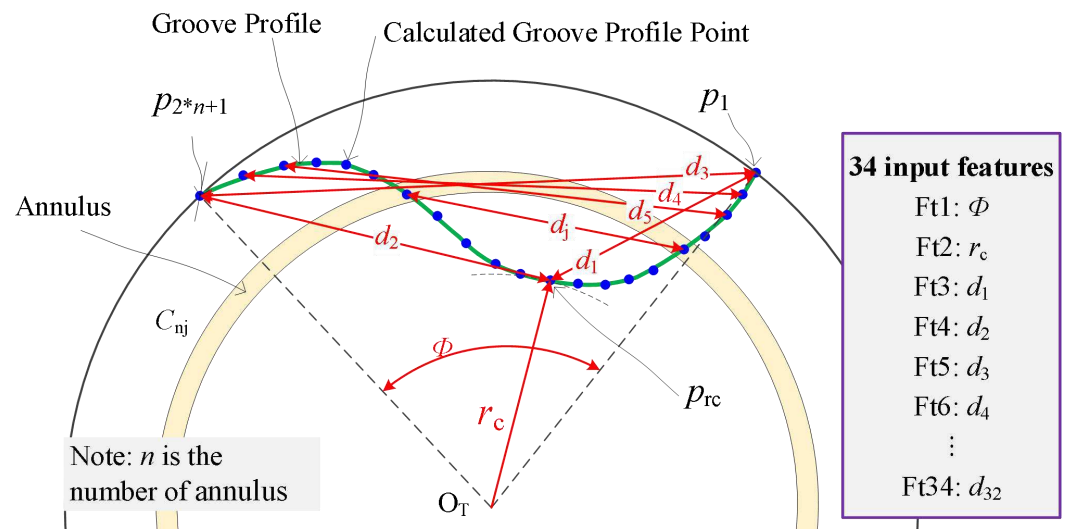

Fig.2 Groove geometry and features

\subsection{Big data generation}

In order to establish MORGM by AI algorithms, two big datasets were established. And for every set, 6 parameters were selected, namely $\Delta \alpha x, \Delta x, \Delta y, \theta_{\mathrm{w}}, g r$ and $B_{\mathrm{W}}$. The wheel diameter $D_{\mathrm{w}}$ was excluded because its influence on the groove could be offset by $\Delta x$.

Then, each parameter was assigned to 6 values. Differently, the first set (denoted as SETA) had a small variable space, and the second set (denoted as SETB) had a big one, as listed in table 1. Thus, every set was consisted of 46656 records and each records included 6 output labels and 34 input features. The structure and some data for SETB was listed in table 2. The corresponding groove geometries for SETA and SETB were presented in Fig.3 and Fig.4.

Table 1 Variables to produce big data SETA and SETB

\begin{tabular}{|c|c|c|c|c|c|}
\hline Labels & $\begin{array}{l}\text { Variable } \\
\text { (unit) }\end{array}$ & $\begin{array}{c}\text { Variable space } \\
\text { of SETA }\end{array}$ & Variables of SETA & $\begin{array}{c}\text { Variable space } \\
\text { of SETB }\end{array}$ & Variables of SETB \\
\hline Lab1 & $\begin{array}{c}\Delta \alpha x \\
(\text { degree })\end{array}$ & {$[35,38]$} & $\begin{array}{l}(35,35.6,36.2 \\
36.8,37.4,38)\end{array}$ & {$[33,40]$} & $\begin{array}{l}(33,34.4,35.8 \\
37.2,38.6,40)\end{array}$ \\
\hline Lab2 & $\begin{array}{c}\Delta \mathrm{x} \\
(\mathrm{mm})\end{array}$ & {$[76,78]$} & $\begin{array}{l}(76,76.4,76.8 \\
77.2,77.6,78)\end{array}$ & {$[75,79]$} & $\begin{array}{c}(75,75.8,76.6 \\
77.4,78.2,79)\end{array}$ \\
\hline Lab3 & $\begin{array}{c}\Delta \mathrm{y} \\
(\mathrm{mm})\end{array}$ & {$[-16,-14]$} & $\begin{array}{l}(-16,-15.6,-15.2 \\
-14.8,-14.4,-14)\end{array}$ & {$[-17,-13]$} & $\begin{array}{l}(-17,-16.2,-15.4 \\
-14.6,-13.8,-13)\end{array}$ \\
\hline Lab4 & $\begin{array}{c}\theta_{\mathrm{W}} \\
\text { (degree) }\end{array}$ & {$[70,80]$} & $\begin{array}{l}(70,72,74 \\
76,78,80)\end{array}$ & {$[65,85]$} & $\begin{array}{l}(65,69,73 \\
77,81,85)\end{array}$ \\
\hline Lab5 & $\begin{array}{c}g r \\
(\mathrm{~mm})\end{array}$ & {$[0,4]$} & $\begin{array}{l}(0,0.8,1.6 \\
2.4,3.2,4)\end{array}$ & {$[0,8]$} & $\begin{array}{l}(0,1.6,3.2 \\
4.8,6.4,8)\end{array}$ \\
\hline Lab6 & $\begin{array}{c}B_{\mathrm{W}} \\
(\mathrm{mm})\end{array}$ & {$[10,30]$} & $\begin{array}{l}(10,14,18, \\
22,26,30)\end{array}$ & {$[10,30]$} & $\begin{array}{l}(10,14,18, \\
22,26,30)\end{array}$ \\
\hline Constan & t parameter & $D_{\mathrm{W}}=75 \mathrm{~mm}$ & & & \\
\hline
\end{tabular}


Table 2 The produced big data structure (SETB)

\begin{tabular}{cccccccccccc}
\hline No. & $\Delta \alpha \mathrm{x}$ & $\Delta \mathrm{x}$ & $\Delta \mathrm{y}$ & $\theta_{\mathrm{W}}$ & $g r$ & $B_{\mathrm{W}}$ & $\mathrm{Ft} 1$ & $\mathrm{Ft} 2$ & $\mathrm{Ft3}$ & $\ldots$ & $\mathrm{Ft} 34$ \\
\hline 1 & 0.628 & 75.8 & -13.0 & 1.484 & 1.6 & 26.0 & 219.357 & 2.433 & 219.357 & $\ldots$ & 3.6989 \\
2 & 0.576 & 75.0 & -14.6 & 1.484 & 1.6 & 10.0 & 146.440 & 1.956 & 146.440 & $\ldots$ & 3.5129 \\
3 & 0.600 & 79.0 & -14.6 & 1.135 & 0.0 & 10.0 & 66.187 & 5.894 & 66.187 & $\ldots$ & 2.1440 \\
$\vdots$ & & & & & & & & & & & \\
46656 & 0.663 & 76.8 & -14.8 & 1.327 & 2.4 & 22.0 & 130.339 & 3.959 & 48.992 & $\ldots$ & 4.0056 \\
\hline
\end{tabular}

Note: the unit of $\Delta \alpha \mathrm{x}$ and $\theta_{\mathrm{w}}$ in this table were rad.

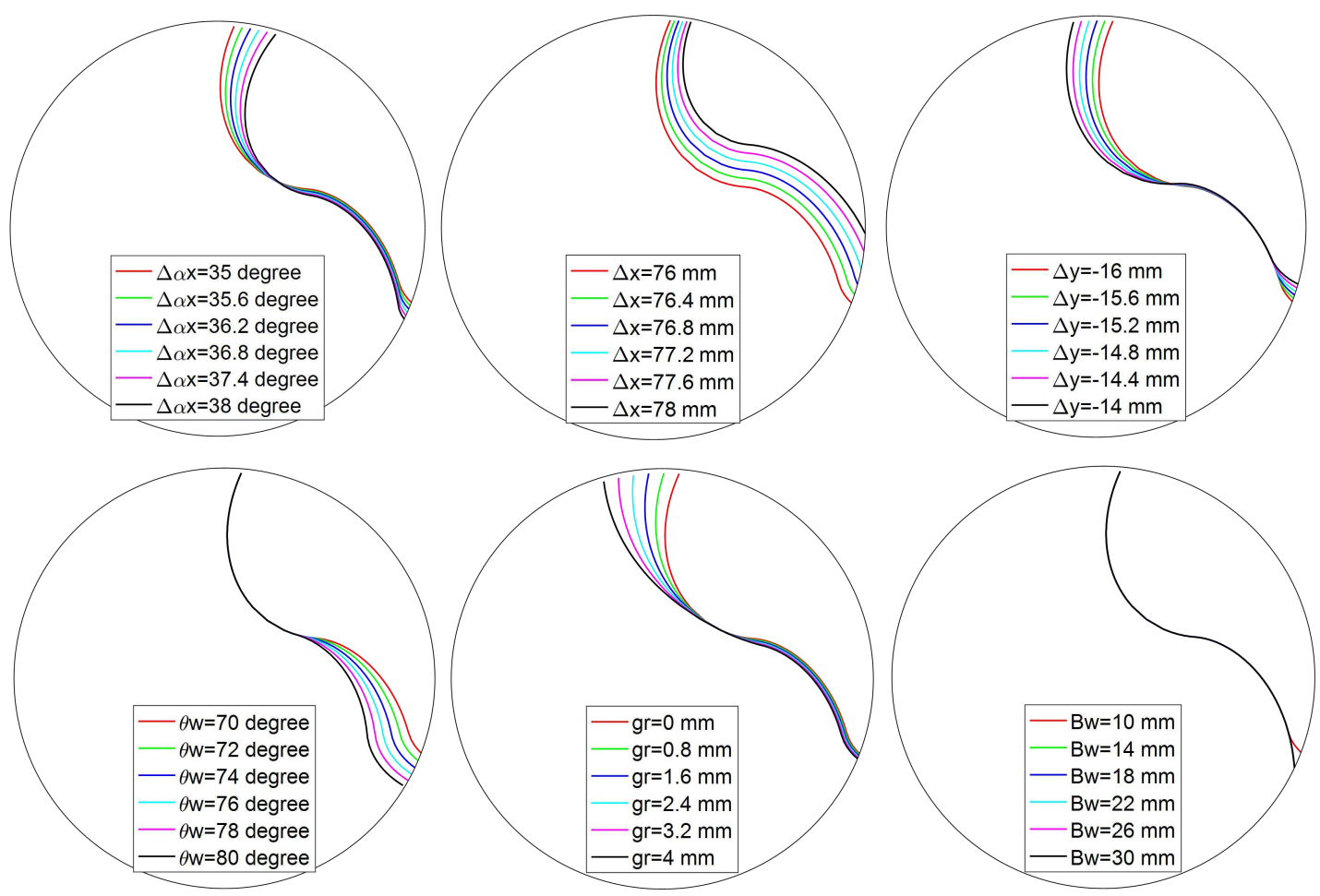

Fig.3 Some typical groove geometries corresponding to SETA

(Initial parameters: $\Delta \alpha x=35, \Delta x=76, \Delta y=-16, \theta_{\mathrm{W}}=70, g r=0$ and $B_{\mathrm{W}}=10$ )

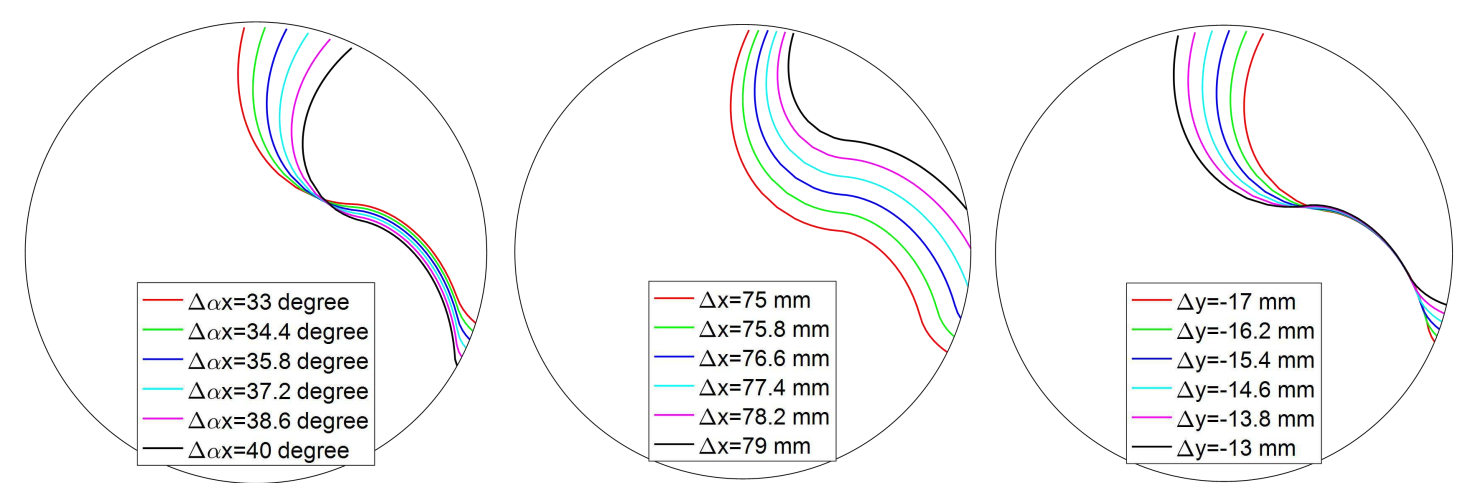




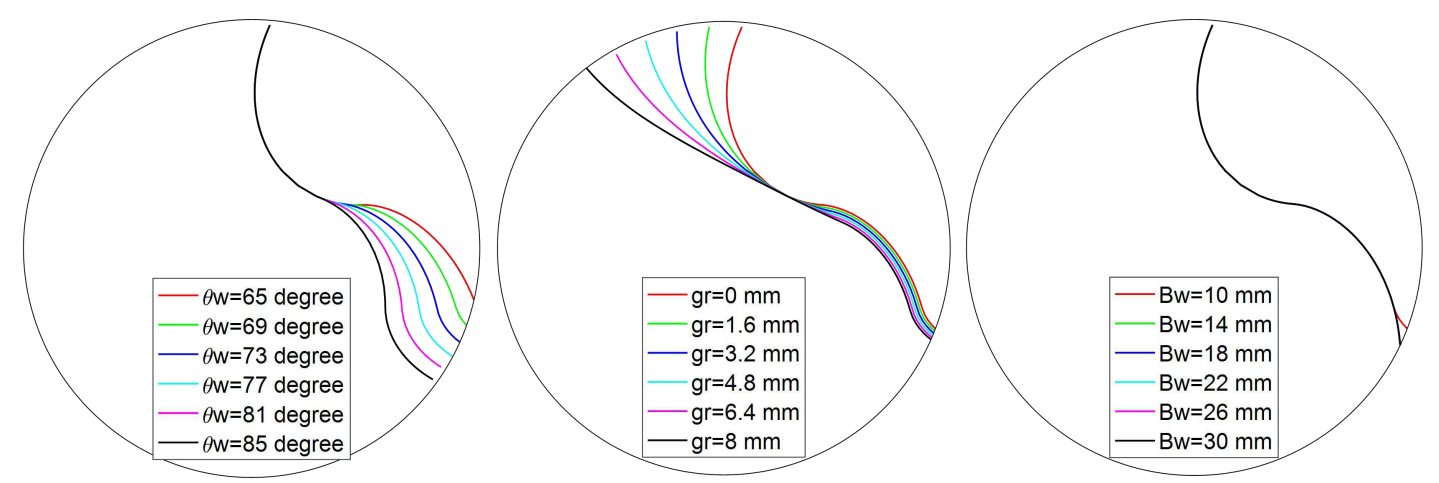

Fig.4 Some typical groove geometries corresponding to SETB (Initial parameters: $\Delta \alpha x=35, \Delta x=76, \Delta y=-16, \theta_{\mathrm{W}}=70, g r=0$ and $B_{\mathrm{W}}=10$ )

\subsection{Big data analysis and feature extraction}

As features would have great impact on the accuracy and efficiency for AI algorithms, the big datasets were analyzed to select efficient features. Dispersion coefficient was a relative statistic to measure the degree of dispersion of data, which was mainly used to compare the degree of dispersion of different sample data. The large dispersion coefficient indicated that the degree of dispersion of data was also large. If the units were different, standard deviation could not be used to compare the degree of dispersion, but the ratio of standard deviation to the mean (relative value) should be used to compare the dispersion. Therefore, coefficient of dispersion $\left(V_{\mathrm{S}}\right)$ for the 34 features were analyzed:

$$
V_{S}=\frac{\sigma}{\mu}
$$

The result was presented in Fig.5. The values of $V_{\mathrm{S}}$ for SETA were between 0.145 and 0.185 . The values of $V_{\mathrm{S}}$ for SETB were between 0.235 and 0.332 . The second and the third features had bigger values than others, but the difference were indistinctively. Thus, all the 34 features were selected. 


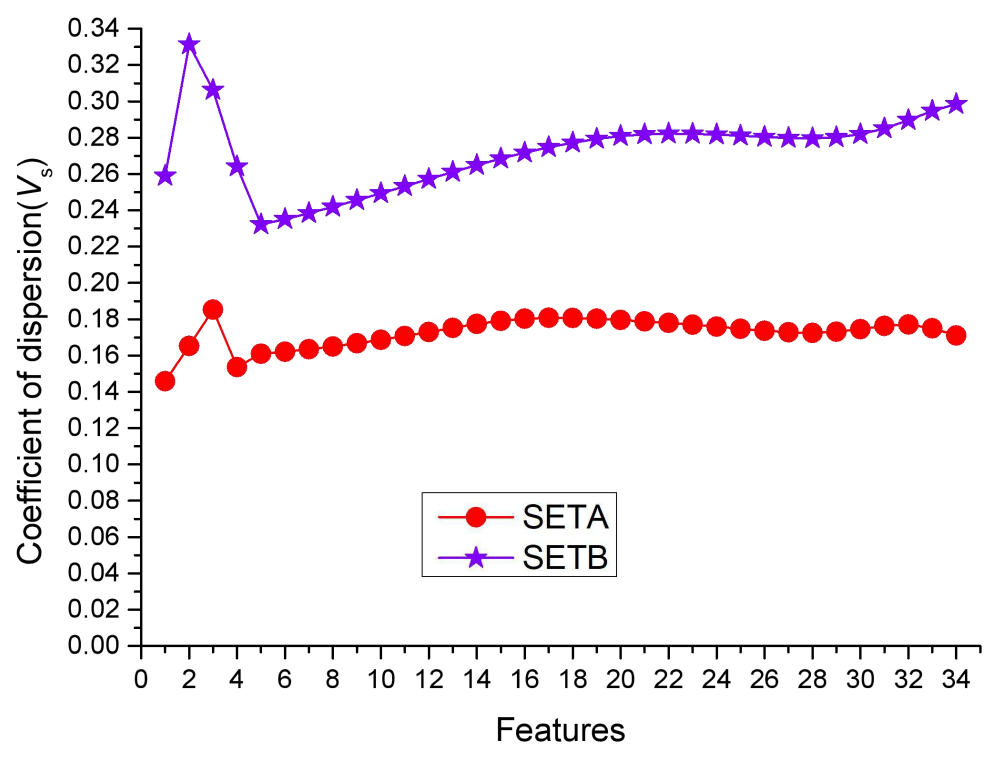

Fig.5 Coefficient of dispersion $\left(V_{\mathrm{S}}\right)$ for the 34 features

\subsection{Data preprocessing}

Considering that the 34 features had different units, the data in the set should be preprocessed. There were usually two ways, one was the standardization method and the other was the normalization method. The standardization method was based on the mean and standard deviation of the raw data:

$$
x^{*}=\frac{x-\mu}{\sigma}
$$

Where, $\mu$ was the mean value and $\sigma$ was the standard deviation.

After processed, all the data were in accordance with standard normal distribution.

Normalization was a way of simplifying the calculation by transforming a dimensionless expression into a dimensionless expression:

$$
x^{*}=\frac{x-x_{\min }}{x_{\max }-x_{\min }}
$$

Where, $x_{\max }$ and $x_{\min }$ were the maximum and minimum values of the data. After processed, all the data were mapped to the range $[0,1]$.

\section{AI methods for MORGM}

The problem discussed in the study was essentially a multiple output regression problem. So far, some algorithms supported multiple output regressions inherently, 
such as linear regression (LR), $k$ nearest-neighbor regression $(k N N)$, decision trees (DTs), random forest regression (RFR) and ANN. However, some algorithms had to be modified to support multiple output, such as SVR. In this paper, the wrapper multiple output regression algorithm and the chained multiple output regression algorithm were used to reconstruct the SVR algorithm respectively. Therefore, seven AI methods was employed to build the MORGM.

\subsection{Linear regression (LR)}

Linear regression fitted a linear model with coefficients $\mathbf{w}=\left(w_{1}, \ldots, w_{\mathrm{p}}\right)$ to minimize the residual sum of squares between the observed targets in the dataset, and the targets predicted by the linear approximation. It tried to build a function that predicts by a linear combination of properties, namely:

$$
\mathbf{y}=\boldsymbol{\omega}^{\mathrm{T}} \mathbf{x}+b
$$

Where, in this study, $\mathbf{y}=($ Lab1; Lab2; Lab3; Lab4; Lab5; Lab6), $\omega=(\omega 1 ; \omega 2 ; .$. ; $\omega 34), \mathbf{x}=(F t 1 ; F t 2 ; F t 3 ; \ldots ; F t 34)$

\section{$3.2 k$-Nearest Neighbor $(k \mathrm{NN})$}

$k$-Nearest Neighbor was a kind of supervised learning methods. It could be used for solving classification and regression problems. The target was predicted based on the $k$ nearest neighbors of each query point. In this study, 5 neighbors (namely, $k=5$ ) and uniform weights were used: that was, each point in the local neighborhood contributes uniformly to the classification of a query point.

\subsection{Random Forest regressor (RFR)}

A random forest was a meta estimator that fits a number of classifying decision trees on various sub-samples of the dataset and uses averaging to improve the predictive accuracy and control over-fitting. In this study, the number of trees in the forest was 10 . The maximum depth of the tree was none, which mean that nodes were expanded until all leaves were pure or until all leaves contained less than 2 samples.

\subsection{Decision trees (DTs)}

Decision Trees (DTs) were a non-parametric supervised learning method used 
for regression. In order to support multi-output problems, decision trees were changed by two ways: (1) store 6 output values in leaves; (2) Use splitting criteria that compute the average reduction across all 7 outputs.

\subsection{SVR-Multi-Output-Regressor (SVR-MOR)}

Support Vector Regression (SVR) was a typical single output model. For this study, it was modified by two methods to meet the multiple output requirement. One was multi target regression strategy and the other is chain strategy.

Multi target regression strategy consists of fitting one regressor per target, which was a commonly used strategy for extending regressors that do not natively support multi-target regression.

\subsection{SVR-Regressor-Chain (SVR-RC)}

The chain strategy was a multi-label model that arranges regressions into a chain. Each model made a prediction in the order specified by the chain using all of the available features provided to the model plus the predictions of models that were earlier in the chain.

\subsection{Artificial Neural Network (ANN)}

The fully-connected artificial neural network was established. It included 7 layers and each layer was consist of 384, 192, 96, 48, 24, 12 and 6 notes. "Sigmoid" was selected as the activation function and "RMSProp" was employed as the optimizer algorithm. The structure of the network was presented in Fig.6.

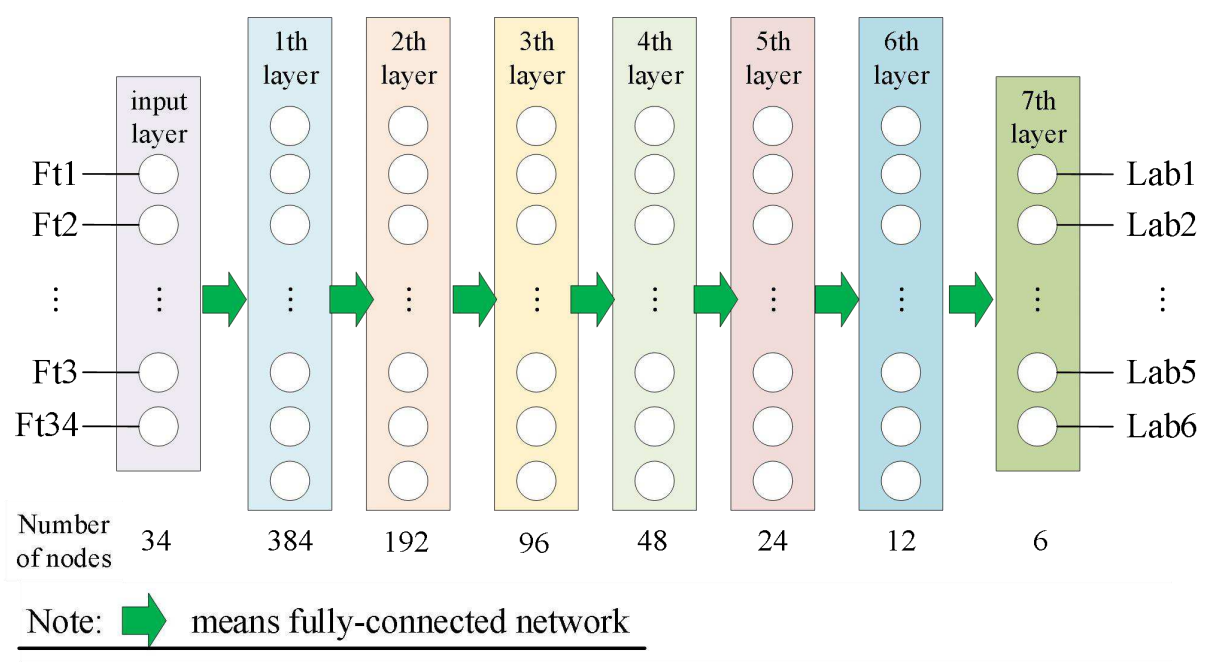


Fig.6 Structure of Artificial Neural Network

\section{Experimental design}

Generally, training datasets, data preprocessing methods and algorithms were main factors for regression models. In order to get the best MORGM, 28 experiments were designed, as listed in table 3. Variables included 2 different datasets, 2 data preprocessing methods and 7 modeling algorithms. To increase readability, all experiments were marked with letters and numbers and divided into 4 groups on average.

Table 3 Experimental design for MORGM

\begin{tabular}{|c|c|c|c|c|c|c|c|c|c|c|c|}
\hline \multirow[t]{2}{*}{ Groups } & \multirow{2}{*}{$\begin{array}{c}\text { No. } \\
1\end{array}$} & \multicolumn{3}{|c|}{ Datasets and methods } & \multirow{2}{*}{$\begin{array}{c}\text { Mark } \\
\text { A1B1C1 }\end{array}$} & \multirow[t]{2}{*}{ Groups } & \multirow{2}{*}{$\begin{array}{c}\text { No. } \\
15\end{array}$} & \multicolumn{3}{|c|}{ Datasets and methods } & \multirow{2}{*}{$\begin{array}{c}\text { Mark } \\
\text { A2B1C1 }\end{array}$} \\
\hline & & A1 & B1 & $\mathrm{C} 1$ & & & & A2 & B1 & $\mathrm{C} 1$ & \\
\hline & 2 & A1 & $\mathrm{B} 1$ & $\mathrm{C} 2$ & $\mathrm{~A} 1 \mathrm{~B} 1 \mathrm{C} 2$ & & 16 & $\mathrm{~A} 2$ & B1 & $\mathrm{C} 2$ & $\mathrm{~A} 2 \mathrm{~B} 1 \mathrm{C} 2$ \\
\hline & 3 & A1 & B1 & $\mathrm{C} 3$ & $\mathrm{~A} 1 \mathrm{~B} 1 \mathrm{C} 3$ & & 17 & $\mathrm{~A} 2$ & B1 & $\mathrm{C} 3$ & $\mathrm{~A} 2 \mathrm{~B} 1 \mathrm{C} 3$ \\
\hline \multirow[t]{7}{*}{ Group1 } & 4 & A1 & B1 & $\mathrm{C} 4$ & A1B1C4 & Group3 & 18 & A2 & B1 & $\mathrm{C} 4$ & $\mathrm{~A} 2 \mathrm{~B} 1 \mathrm{C} 4$ \\
\hline & 5 & A1 & B1 & $\mathrm{C} 5$ & A1B1C5 & & 19 & $\mathrm{~A} 2$ & B1 & $\mathrm{C} 5$ & $\mathrm{~A} 2 \mathrm{~B} 1 \mathrm{C} 5$ \\
\hline & 6 & A1 & B1 & $\mathrm{C} 6$ & A1B1C6 & & 20 & A2 & B1 & C6 & A2B1C6 \\
\hline & 7 & A1 & B1 & $\mathrm{C} 7$ & $\mathrm{~A} 1 \mathrm{~B} 1 \mathrm{C} 7$ & & 21 & $\mathrm{~A} 2$ & B1 & $\mathrm{C} 7$ & $\mathrm{~A} 2 \mathrm{~B} 1 \mathrm{C} 7$ \\
\hline & 8 & A1 & B2 & $\mathrm{C} 1$ & $\mathrm{~A} 1 \mathrm{~B} 2 \mathrm{C} 1$ & & 22 & $\mathrm{~A} 2$ & B2 & $\mathrm{C} 1$ & $\mathrm{~A} 2 \mathrm{~B} 2 \mathrm{C} 1$ \\
\hline & 9 & A1 & $\mathrm{B} 2$ & $\mathrm{C} 2$ & $\mathrm{~A} 1 \mathrm{~B} 2 \mathrm{C} 2$ & & 23 & $\mathrm{~A} 2$ & $\mathrm{~B} 2$ & $\mathrm{C} 2$ & $\mathrm{~A} 2 \mathrm{~B} 2 \mathrm{C} 2$ \\
\hline & 10 & A1 & $\mathrm{B} 2$ & $\mathrm{C} 3$ & $\mathrm{~A} 1 \mathrm{~B} 2 \mathrm{C} 3$ & & 24 & $\mathrm{~A} 2$ & B2 & $\mathrm{C} 3$ & $\mathrm{~A} 2 \mathrm{~B} 2 \mathrm{C} 3$ \\
\hline \multirow[t]{4}{*}{ Group2 } & 11 & $\mathrm{~A} 1$ & B2 & $\mathrm{C} 4$ & $\mathrm{~A} 1 \mathrm{~B} 2 \mathrm{C} 4$ & Group4 & 25 & $\mathrm{~A} 2$ & B2 & $\mathrm{C} 4$ & $\mathrm{~A} 2 \mathrm{~B} 2 \mathrm{C} 4$ \\
\hline & 12 & $\mathrm{~A} 1$ & B2 & $\mathrm{C} 5$ & A1B2C5 & & 26 & $\mathrm{~A} 2$ & B2 & $\mathrm{C} 5$ & A2B $2 \mathrm{C} 5$ \\
\hline & 13 & A1 & B2 & C6 & A1B2C6 & & 27 & A2 & B2 & C6 & A2B2C6 \\
\hline & 14 & A1 & B2 & $\mathrm{C} 7$ & $\mathrm{~A} 1 \mathrm{~B} 2 \mathrm{C} 7$ & & 28 & $\mathrm{~A} 2$ & B2 & $\mathrm{C} 7$ & $\mathrm{~A} 2 \mathrm{~B} 2 \mathrm{C} 7$ \\
\hline
\end{tabular}

Note: Datasets (A1: SETA; A2: SETB); Data preprocessing (B1: normalization; B2: standardization); Methods (C1: LR; C2: kNN; C3: RFR; C4: DT; C5: SVR-MOR; C6: SVR-RC; C7: ANN)

Based on the datasets introduced in section 2.2, all the 46656 records were divided into two sets. One was the training set including 40000 records and the other was the testing sets including 6656 records.

All the algorithms were implemented by Python 3.9.1 and Keras 2.4.0 with Tensorflow2.4.1 as their backend, and running on one Intel(R) UHD Graphics GPU. The server operating system was Windows 10. The functions corresponding to the 7 approaches were listed in table 4 .

Table 4 Functions corresponding to approaches

\begin{tabular}{ll}
\hline Approaches & Functions \\
\hline
\end{tabular}




\begin{tabular}{ll}
\hline LR & sklearn.linear_model.LinearRegression () \\
$k \mathrm{NN}$ & sklearn.neighbors.KNeighborsRegressor() \\
RFR & sklearn.ensemble.RandomForestRegressor() \\
DT & sklearn.tree.DecisionTreeRegressor() \\
SVR-MOR & $\bullet$ sklearn.svm.LinearSVR() \\
& $\bullet$ sklearn.multioutput.MultiOutputRegressor() \\
SVR-RC & $\bullet$ sklearn.svm.LinearSVR() \\
& $\bullet$ sklearn.multioutput.RegressorChain() \\
ANN & keras.models.Sequential() \\
\hline
\end{tabular}

\section{Results and discussion}

\subsection{Model Performance Metrics}

Generally, mean square error (MSE), mean absolute error (MAE) and R square $\left(\mathrm{R}^{2}\right)$ were used to evaluate regression models. Considering that they had the similar effects, MSE was selected, and the best model would have the minimum MSE, because the smaller MSE means the better accurate. Therefore, the next work was to find the minimum MSE from the 28 experiments.

The result of MSEs for the 28 experiments was listed in Table 5. The 6 labels were analyzed respectively, as shown in Fig.7. Obviously, Lab6 had the largest MSE nearly for all the 28 experiments. It was because that there were only two valid samples for Lab6 (as shown in Fig.3 and Fig.4), which was insufficient to establish a regression model. Besides, according to Fig.4, Lab6 (i.e., the thickness of the wheel) had little impact on the groove. Therefore, Lab6 was removed from label groups and the average of the prior 5 labels were used for evaluation. For convenience, the symbol "SME" means the average of the prior 5 labels in the following section.

Table 5. Values of MSE for the 28 experiments

\begin{tabular}{ccccccccc}
\hline No. & Mark & Lab1 & Lab2 & Lab3 & Lab4 & Lab5 & Lab6 & $\begin{array}{c}\text { MSE } \\
\text { (Average, } \\
\text { except Lab6) }\end{array}$ \\
\hline 1 & A1B1C1 & 0.08955 & 0.00934 & 0.10263 & 0.00309 & 0.00309 & 0.07181 & $\mathbf{0 . 0 4 3 4 4 9}$ \\
2 & A1B1C2 & 0.00495 & 0.00114 & 0.01405 & 0.00021 & 0.00005 & 0.11067 & $\mathbf{0 . 0 0 5 0 8 7}$ \\
3 & A1B1C3 & 0.00361 & 0.00146 & 0.01509 & 0.00051 & 0.00005 & 0.10640 & $\mathbf{0 . 0 0 5 1 6 9}$ \\
4 & A1B1C4 & 0.01045 & 0.00325 & 0.02978 & 0.00184 & 0.00026 & 0.17556 & $\mathbf{0 . 0 1 1 3 3 1}$ \\
5 & A1B1C5 & 0.09308 & 0.00941 & 0.10453 & 0.00312 & 0.00321 & 0.07294 & $\mathbf{0 . 0 4 4 6 6}$ \\
\hline
\end{tabular}




\begin{tabular}{|c|c|c|c|c|c|c|c|c|}
\hline 6 & A1B1C6 & 0.09291 & 0.00956 & 0.10487 & 0.00327 & 0.00331 & 0.07245 & 0.044559 \\
\hline 7 & $\mathrm{~A} 1 \mathrm{~B} 1 \mathrm{C} 7$ & 0.00222 & 0.00050 & 0.00354 & 0.00020 & 0.00012 & 0.11733 & 0.001613 \\
\hline 8 & $\mathrm{~A} 1 \mathrm{~B} 2 \mathrm{C} 1$ & 0.76760 & 0.08007 & 0.87966 & 0.02653 & 0.02652 & 0.61551 & 0.372424 \\
\hline 9 & $\mathrm{~A} 1 \mathrm{~B} 2 \mathrm{C} 2$ & 0.08072 & 0.01867 & 0.21830 & 0.00303 & 0.00052 & 0.90391 & 0.080179 \\
\hline 10 & $\mathrm{~A} 1 \mathrm{~B} 2 \mathrm{C} 3$ & 0.03106 & 0.01240 & 0.12974 & 0.00449 & 0.00045 & 0.91573 & 0.044421 \\
\hline 11 & $\mathrm{~A} 1 \mathrm{~B} 2 \mathrm{C} 4$ & 0.08736 & 0.02746 & 0.25771 & 0.01561 & 0.00185 & 1.48094 & 0.097034 \\
\hline 12 & $\mathrm{~A} 1 \mathrm{~B} 2 \mathrm{C} 5$ & 0.79103 & 0.08261 & 0.89320 & 0.02691 & 0.02921 & 0.62529 & 0.382036 \\
\hline 13 & A1B2C6 & 0.79098 & 0.08537 & 0.94591 & 0.02859 & 0.02759 & 0.62118 & 0.381530 \\
\hline 14 & $\mathrm{~A} 1 \mathrm{~B} 2 \mathrm{C} 7$ & 0.01143 & 0.00212 & 0.02033 & 0.00063 & 0.00110 & 0.57225 & 0.008746 \\
\hline 15 & $\mathrm{~A} 2 \mathrm{~B} 1 \mathrm{C} 1$ & 0.10030 & 0.00836 & 0.09507 & 0.00667 & 0.00667 & 0.08056 & 0.047667 \\
\hline 16 & $\mathrm{~A} 2 \mathrm{~B} 1 \mathrm{C} 2$ & 0.01504 & 0.00153 & 0.01892 & 0.00032 & 0.00048 & 0.11721 & 0.008992 \\
\hline 17 & $\mathrm{~A} 2 \mathrm{~B} 1 \mathrm{C} 3$ & 0.00942 & 0.00147 & 0.01615 & 0.00054 & 0.00025 & 0.11243 & 0.006892 \\
\hline 18 & $\mathrm{~A} 2 \mathrm{~B} 1 \mathrm{C} 4$ & 0.02191 & 0.00349 & 0.03330 & 0.00213 & 0.00087 & 0.18502 & 0.015207 \\
\hline 19 & $\mathrm{~A} 2 \mathrm{~B} 1 \mathrm{C} 5$ & 0.10102 & 0.00860 & 0.09675 & 0.00701 & 0.00735 & 0.08442 & 0.049282 \\
\hline 20 & $\mathrm{~A} 2 \mathrm{~B} 1 \mathrm{C} 6$ & 0.10089 & 0.00852 & 0.09675 & 0.00797 & 0.00726 & 0.08435 & 0.049397 \\
\hline 21 & $\mathrm{~A} 2 \mathrm{~B} 1 \mathrm{C} 7$ & 0.01960 & 0.00171 & 0.01894 & 0.00068 & 0.00030 & 0.06914 & 0.010233 \\
\hline 22 & $\mathrm{~A} 2 \mathrm{~B} 2 \mathrm{C} 1$ & 0.94212 & 0.07795 & 0.88628 & 0.06222 & 0.05701 & 0.69049 & 0.429235 \\
\hline 23 & $\mathrm{~A} 2 \mathrm{~B} 2 \mathrm{C} 2$ & 0.15130 & 0.01503 & 0.18622 & 0.00318 & 0.00431 & 0.99143 & 0.089216 \\
\hline 24 & $\mathrm{~A} 2 \mathrm{~B} 2 \mathrm{C} 3$ & 0.08363 & 0.01353 & 0.14854 & 0.00515 & 0.00216 & 0.96575 & 0.062712 \\
\hline 25 & $\mathrm{~A} 2 \mathrm{~B} 2 \mathrm{C} 4$ & 0.18351 & 0.03329 & 0.31464 & 0.01877 & 0.00755 & 1.60833 & 0.137554 \\
\hline 26 & $\mathrm{~A} 2 \mathrm{~B} 2 \mathrm{C} 5$ & 0.94893 & 0.07950 & 0.89652 & 0.06381 & 0.06213 & 0.72106 & 0.440222 \\
\hline 27 & $\mathrm{~A} 2 \mathrm{~B} 2 \mathrm{C} 6$ & 0.95102 & 0.08097 & 0.91379 & 0.06957 & 0.06259 & 0.73013 & 0.448615 \\
\hline 28 & $\mathrm{~A} 2 \mathrm{~B} 2 \mathrm{C} 7$ & 0.05924 & 0.00796 & 0.07057 & 0.00259 & 0.00262 & 0.57382 & 0.035098 \\
\hline
\end{tabular}

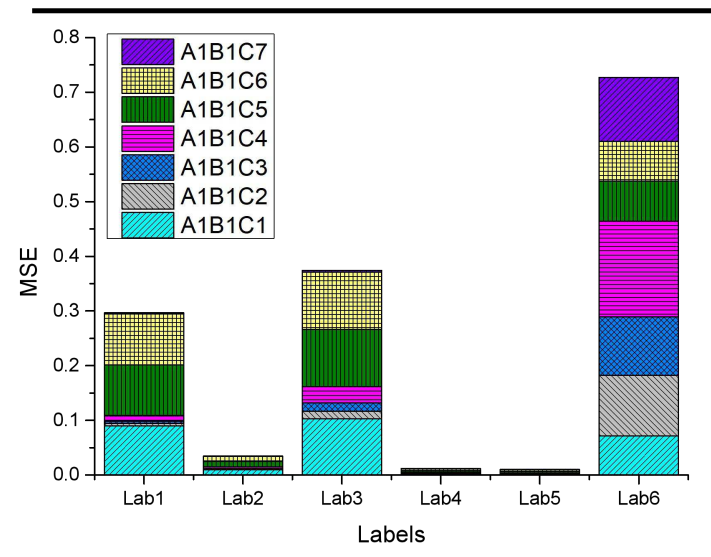

(a) MSE for Group1

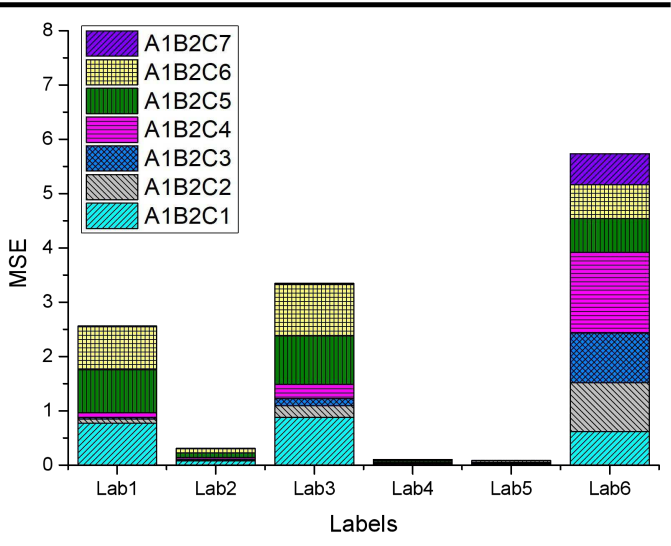

(b) MSE for Group2 


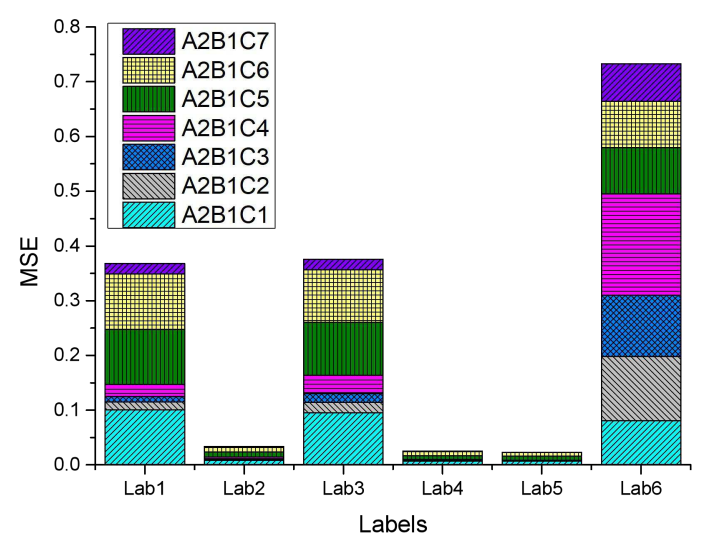

(c) MSE for Group3

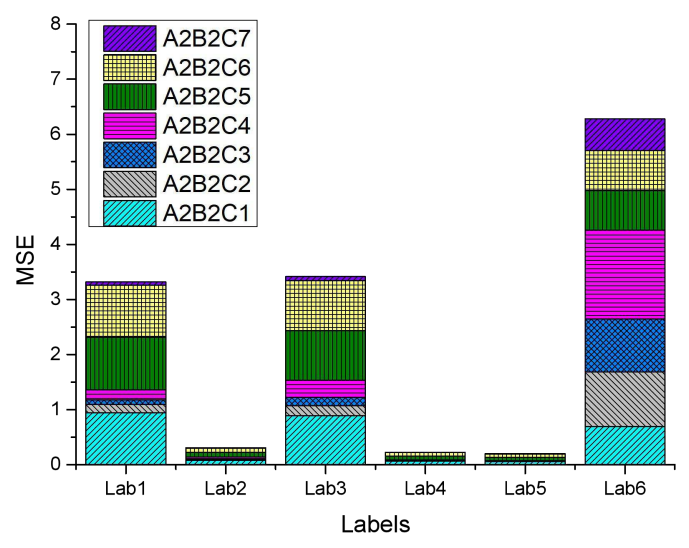

(d) MSE for Group4

Fig. 7 Values of MSE for the 28 experiments

\subsection{Datasets analysis}

As dataset was a foundation for a regression model, SETA and SETB were used to evaluate the influence of dataset on MORGM.

The results were presented in Fig.8. It indicated that MSE changed with different datasets and SETA (signed as A1) performed better than SETB (signed as A2). Besides, the change rate corresponding to the 7 methods were also different. It changed little for C1, C5 and C6 methods (under 20\%). While it reached more than $300 \%$ for $\mathrm{C} 7$. Thus, datasets would have little impact on the MORGM by using C1, C5 and C6 methods and have great impact by using C7 method.

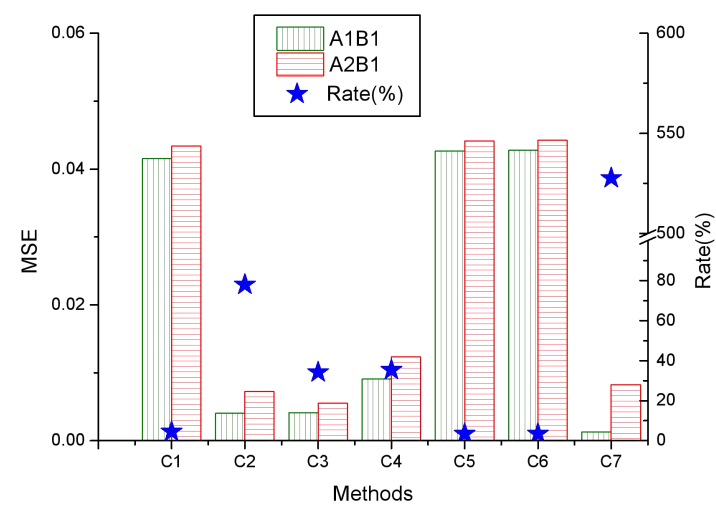

(a) MSE with the same standardization method $($ Rate $=(\mathrm{A} 2 \mathrm{~B} 1-\mathrm{A} 1 \mathrm{~B} 1) / \mathrm{A} 1 \mathrm{~B} 1)$

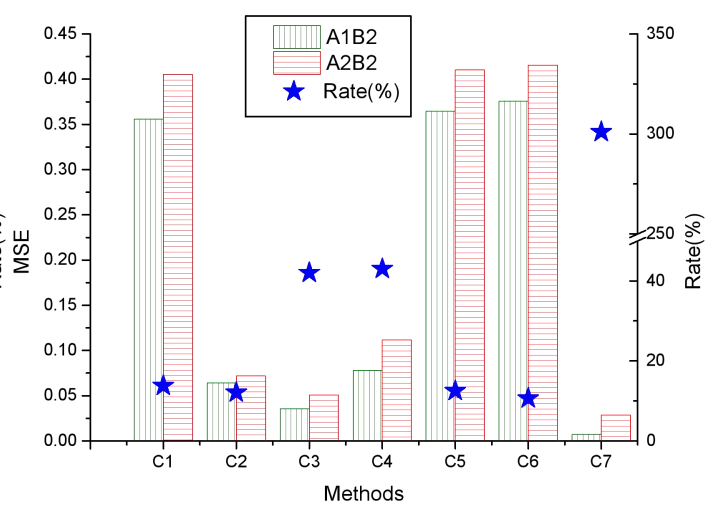

(b) MSE with the same normalization method $($ Rate $=(\mathrm{A} 2 \mathrm{~B} 2-\mathrm{A} 1 \mathrm{~B} 2) / \mathrm{A} 1 \mathrm{~B} 2)$

Fig.8 MSE values for different datasets

\subsection{Data preprocessing analysis}

The influence of standardization and normalization methods on MSE were analyzed, as shown in Fig.9. the results showed that B1 was much better than B2 for 
all the 7 methods, as well as for all the 2 datasets. Therefore, B1 (normalization) method was selected to build MORGM.

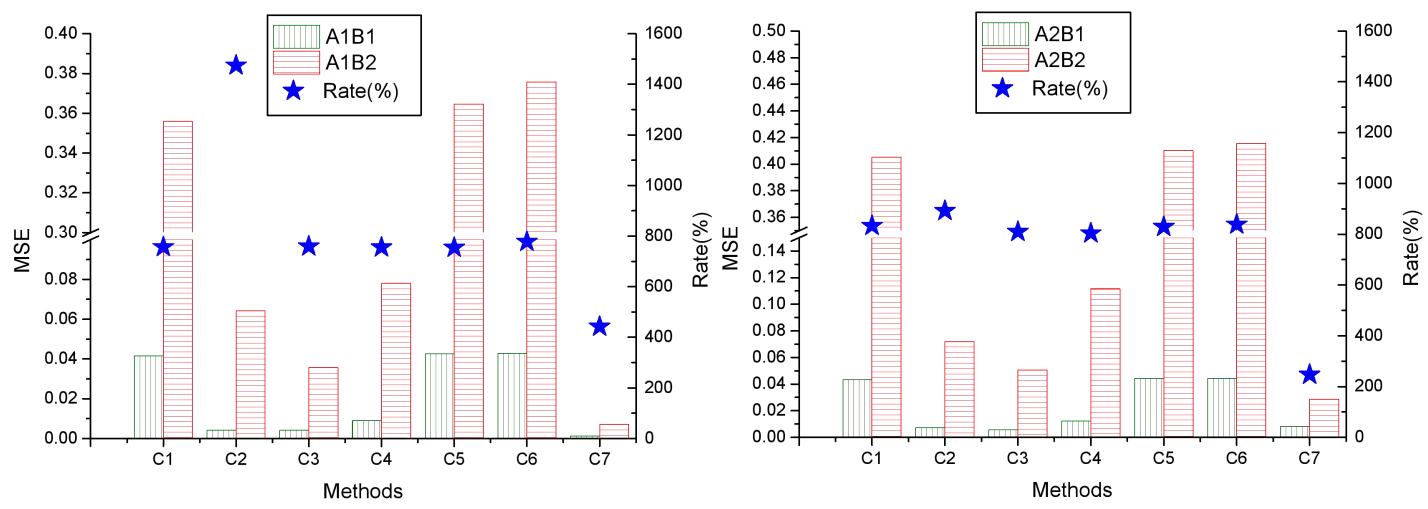

Fig.9 Impact of data preprocessing method on accuracy

\subsection{AI methods analysis}

The average MSE of the prior 5 labels were used to compare the performances of the 7 methods, as shown in Fig.10. It indicated that C1, C5 and C6 had poor performances. While, C2, C3, C4 and C7 had good accurate, and C7 was the best among them. Therefore, C7 (ANN) method was selected to build MORGM.

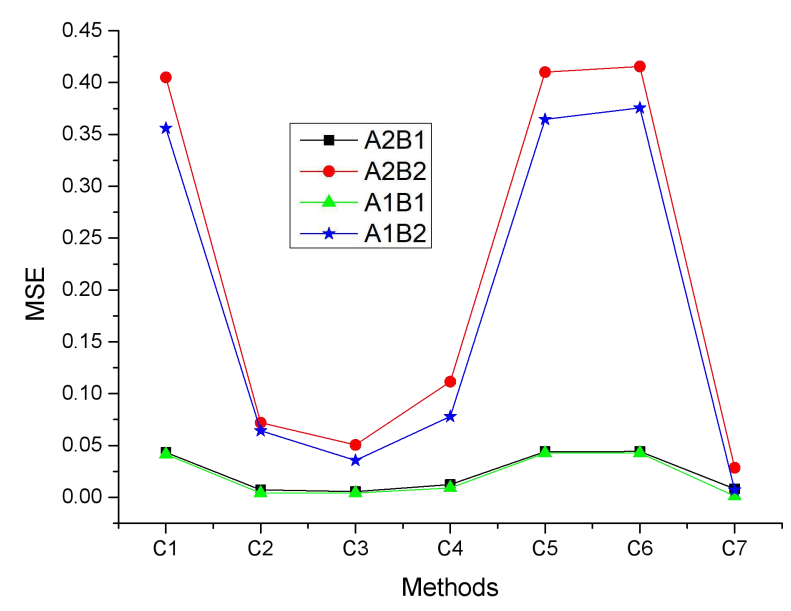

Fig.10 comparison of MSE between different methods

\subsection{Modeling and validating of MORGM}

As has been discussed above, MORGM was built by the ANN methods (C7) and the normalization method (B1) was selected to preprocess the datasets. The MORGM have high accuracy both for SETA and SETB (see Fig. 10).

The biggest MSE of the testing set (including 6656 records) that produced by 
A1B1C7 was picked out, as listed in table 6. It showed that the biggest MSE value was 0.0256 , which was so little for a multi-output regression model. Furthermore, two grooves that machined respectively with true and predicted parameters were plotted in Fig.11. It showed that the groove produced by the predicted parameters was in good consistence with the true parameters.

Table 6 Results corresponding to the biggest MSE produced by A1B1C7

\begin{tabular}{cccccc}
\hline & Lab1 & Lab2 & Lab3 & Lab4 & Lab5 \\
\hline True value & 0.610865 & 76 & -16 & 1.221731 & 0.8 \\
Predicted value & 0.612814 & 75.97774 & -16.0003 & 1.222485 & 0.825596 \\
MSE & & & 0.0256 & & \\
\hline
\end{tabular}
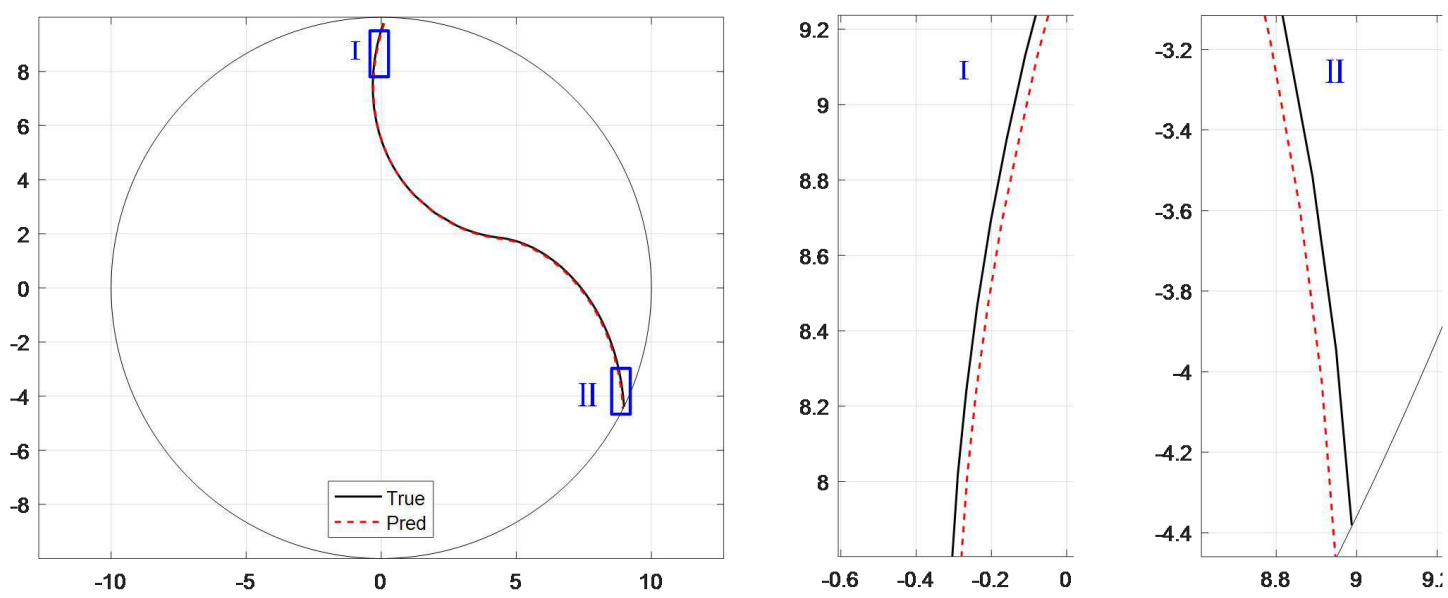

Fig.11 Comparation of grooves produced by true and predicted parameters

\section{Conclusion}

In order to meet the increasing manufacturing requirements of diverse cutting tool grooves, MORGM was established based on AI algorithms and big data technology. So that the CMP could be readily calculated to manufacture the desired groove. The main contributions can be concluded as:

(1) Different from previous studies, the groove geometry was determined by 34 features, which could recognize the groove more exactly and be more appropriate for AI algorithms.

(2) Big data of groove machining process was built, which was consisted of 46656 records and each records concluding 6 output labels and 34 input features. It would be a valuable data resource for groove machining. 
(3) MORGM was built by the ANN algorithm and the normalization data preprocess method. And the wheel position and geometry could be readily calculated by the desired groove. The results showed that the built MORGM had high accuracy and will have wide application prospect in groove manufacture.

\section{References:}

[1] D.S. Sheth, S. Malkin, CAD/CAM for Geometry and Process Analysis of Helical Groove Machining, CIRP Annals 39 (1990) 129-132.

[2] G. Li, L. Dai, J. Liu, H. Zhou, G. Tian, L. Li, An approach to calculate grinding wheel path for complex end mill groove grinding based on an optimization algorithm, Journal of Manufacturing Processes 53 (2020) 99-109.

[3] J.H. Kim, J.W. Park, T.J. Ko, End mill design and machining via cutting simulation, COMPUTER-AIDED DESIGN 40 (2008) 324-333.

[4] M.M. Rababah, Z.C. Chen, An Automated and Accurate CNC Programming Approach to Five-Axis Flute Grinding of Cylindrical End-Mills Using the Direct Method, Journal of Manufacturing Science and Engineering 135 (2013).

[5] L. Ren, S. Wang, L. Yi, A Generalized and Efficient Approach for Accurate Five-Axis Flute Grinding of Cylindrical End-Mills, Journal of Manufacturing Science and Engineering 140 (2018).

[6] V.H. Nguyen, S.L. Ko, Determination of workpiece profile and influence of singular point in helical grooving, CIRP Annals 62 (2013) 323-326.

[7] T.T. Pham, S.L. Ko, A manufacturing model of an end mill using a five-axis CNC grinding machine, The International Journal of Advanced Manufacturing Technology 48 (2010) 461-472.

[8] S. Xiao, L. Wang, Z.C. Chen, S. Wang, A. Tan, A New and Accurate Mathematical Model for Computer Numerically Controlled Programming of 4Y1 Wheels in $2 \frac{1}{2}$-Axis Flute Grinding of Cylindrical End-Mills, Journal of Manufacturing Science and Engineering 135 (2013).

[9] F. Tang, J. Bai, X. Wang, Practical and reliable carbide drill grinding methods based on a five-axis CNC grinder, The International Journal of Advanced Manufacturing Technology 73 (2014) 659-667.

[10] K. Jia, J. Hong, S. Zheng, Y. Zhang, An approach on wheel position and orientation calculation for helical broaching tool sharpening, The International Journal of Advanced Manufacturing Technology 92 (2017) 1991-2000.

[11] Z. Chen, W. Ji, G. He, X. Liu, L. Wang, Y. Rong, Iteration based calculation of position and orientation of grinding wheel for solid cutting tool flute grinding, Journal of Manufacturing Processes 36 (2018) 209-215.

[12] L. Wang, Z.C. Chen, J. Li, J. Sun, A novel approach to determination of wheel position and orientation for five-axis $\mathrm{CNC}$ flute grinding of end mills, The International Journal of Advanced Manufacturing Technology 84 (2016) 2499-2514.

[13] L. Ren, S. Wang, L. Yi, S. Sun, An accurate method for five-axis flute grinding 
in cylindrical end-mills using standard 1V1/1A1 grinding wheels, Precision engineering 43 (2016) 387-394.

[14] B. Karpuschewski, K. Jandecka, D. Mourek, Automatic search for wheel position in flute grinding of cutting tools, CIRP Annals 60 (2011) 347-350.

[15] G. Li, H. Zhou, X. Jing, G. Tian, L. Li, An intelligent wheel position searching algorithm for cutting tool grooves with diverse machining precision requirements, International Journal of Machine Tools and Manufacture 122 (2017) 149-160.

[16] M. Habibi, Z.C. Chen, A Generic and Efficient Approach to Determining Locations and Orientations of Complex Standard and Worn Wheels for Cutter Flute Grinding Using Characteristics of Virtual Grinding Curves, JOURNAL OF MANUFACTURING SCIENCE AND ENGINEERING-TRANSACTIONS OF THE ASME 139 (2017).

[17] Y. Fang, L. Wang, J. Yang, J. Li, An Accurate and Efficient Approach to Calculating the Wheel Location and Orientation for CNC Flute-Grinding, Applied Sciences 10 (2020) 4223.

[18] X. Liu, Z. Chen, W. Ji, L. Wang, Iteration-based error compensation for a worn grinding wheel in solid cutting tool flute grinding, Procedia Manufacturing 34 (2019) 161-167.

[19] X. Liu, Z. Chen, W. Ji, L. Wang, A compensation method for wheel wear in solid cutting tool groove grinding based on iteration algorithm, The International Journal of Advanced Manufacturing Technology 107 (2020) 3389-3399.

[20] E. Uhlmann, N. Schröer, A. Muthulingam, B. Gülzow, Increasing the productivity and quality of flute grinding processes through the use of layered grinding wheels, Procedia Manufacturing 33 (2019) 754-761.

[21] M. Wasif, S.A. Iqbal, A. Ahmed, M. Tufail, M. Rababah, Optimization of simplified grinding wheel geometry for the accurate generation of end-mill cutters using the five-axis CNC grinding process, The International Journal of Advanced Manufacturing Technology 105 (2019) 4325-4344. 